\title{
Modeling Long Memory in The Indian Stock Market using Fractionally Integrated Egarch Model
}

\author{
Hojatallah Goudarzi
}

\begin{abstract}
The weak form of market efficiency assumes that prediction of asset returns based on historical information's is not possible. Nevertheless, a great number of studies show that asset returns exhibit significant autocorrelation between observations widely separated in time. This is one of the stylized facts of financial markets which is known as long memory. The presence of long memory can be defined in term of persistence of autocorrelation. This paper studies the presence of long memory property in the Indian stock market. Using data from BSE500 stock index, this study found evidence of long memory property in the Indian stock market as seen in developed stock markets and some other emerging markets. It is found that the FIEGARCH $(1, d, 1)$ is the best fit model and it outperforms other ARCH-type models in modelling volatility in the Indian stock market.
\end{abstract}

Index Terms-Asset Returns, Volatility, Fractionally Integrated EGARCH, Long Memory

\section{INTRODUCTION}

The statistical analysis of financial time series provides evidence of various stylized facts, i.e. volatility clustering, mean reversion, fat tails and leverage effects, among which volatility clustering has received considerable attention. Many models have been added throughout the years to the Autoregressive Conditional Heteroskedasticity (ARCH) family, following the seminal paper by [1], which capture the short-run dependency of the conditional variances [2].

It is generally accepted that many time series of practical interest exhibit strong dependence, i.e., long memory. For such series, the sample autocorrelations decay slowly. This necessitates a class of models for describing such behavior. A popular class of such models is the autoregressive fractionally integrated moving average (ARFIMA) of [3], [4], and [5] which is a linear process. However, there is also a need for nonlinear long memory models [6].

Among the empirical regularities which volatility models try to capture, one is that the decay exhibited by estimated conditional variances seems to be decreasing hyperbolically rather than exponentially. Another way of expressing this feature is that the process possesses long memory properties in the conditional variance [2].

To capture long-range dependence in volatility, [7] and [7] propose fractionally integrated autoregressive conditional heteroskedasticity (ARCH) models. In this class of model,

$\mathrm{PhD}$ Scholar, University of Mysore, Mysore, India(email:hg502003@yahoo.com). fractional integration, suggested by [3] and [5] for processes for the mean are applied to a GARCH framework [6]. The fractionally integrated GARCH (FIGARCH) model of [7] can be viewed as a fractionally integrated ARMA (ARFIMA) specification for the squared innovations. Like the fractionally integrated class of processes $I(d)$, introduced by [3], [4], and [5] the FIGARCH model avoids the sharp distinction between $I(0)$ and $I(1)$ processes by allowing $d$ to take a value between 0 and 1 . Therefore, the ACF of the volatility process can possess a rate of decay somewhere between the extremes of an exponential rate $(I(0))$ and infinite persistence $(I(1))[9]$. Extensions to the FIGARCH specification include[7] who propose an exponential version (FIEGARCH) while [10] extend the parameterization to include the asymmetric power ARCH structure of [11]. The FIGARCH model has been successfully applied in several areas of empirical finance. Ref.[12] investigate the economic value of FIEGARCH forecasts of volatility, while [13] extend the model to a bivariate framework, and [14] and [15] study high frequency data with the model[9].

The advantage of modelling long memory applied to volatility processes is that the forecasting properties of the model so derived better suit the needs of medium-to-long term prediction which is crucial in derivative pricing models. One class of models that was suggested in this direction is the so-called Fractionally Integrated GARCH (FIGARCH) process in which the ideas of fractional integration suggested by [3] and [5] for processes for the mean are applied to a GARCH framework. Fractional integration serves the purpose of extending ARIMA processes to a more general class, ARFIMA, giving a continuum of possibilities between the polar cases of unit roots processes and of integrated processes of order 0 . The order of integration in such a case becomes a real parameter $d$ assuming values between 0 and 1 which can be estimated in the time or in the frequency domain [2].

The purpose of this study is to examine the long memory feature of the volatility of returns for the BSE index which is one of the Indian Stock Market indices using FIEGARCH model.

The remainder of this paper is organized as follows. Review of the literature is presented in section 2 . We review the volatility models in section 3 . The next section describes the estimation and testing procedures for long memory, and empirical results are discussed in Section 5. The final section provides a brief conclusion.

\section{LITERATURE REVIEW}

Ref. [7] proposed Figarch model to capture long-range 
dependence in volatility. Standard models of the conditional variance implied an exponential rate of decay for autocorrelation function of squared innovations. For example, the GARCH $(1,1)$ model possess this feature and cannot capture the degree of persistence in the sample ACF of absolute returns. Typically autocorrelations from a GARCH $(1,1)$ model start too high and decay much faster than the data implies. This observation has been used to conclude that standard volatility models, such as the GARCH $(p, q)$ class, are unable to account for the longrange dependence found in measures of volatility.

Ref.[12] in an article entitled "Modelling and pricing long memory in stock market volatility" proposed a new class of more flexible fractionally integrated EGARCH (FIEGARCH) models for characterizing the long-run dependencies in the US stock market volatility. They found that the conditional variance for the S\&P500 composite index is best modeled as a mean reverting fractionally integrated process.

Ref.[16] in their paper entitled "Long memory in the Greek stock market", using the spectral regression method, found significant evidence of fractional dynamics with longmemory features in the stock returns series of emerging capital markets, at the Athens stock exchange in Greece. They found that price movement in the GSM appears to be influenced by realizations from both the recent past and the remote past. The out-of-sample long-memory forecasting resulted in significant improvements in forecasting accuracy (especially over longer horizons). Compared with RW forecast long-memory forecast also dominated autoregressive forecasts for horizons exceeding 6 month. This evidence contradicted the martingle model, which states that conditioning on horizontal returns is unpredictable. The practical usefulness of developing longmemory models for the GSM was therefore established. They concluded that the long-memory evidence obtained for the Greek stock market is in sharp contrast to that obtained for major capital markets. This suggested the possibility of differential long-term stochastic behavior between major and emerging capital markets. Their findings suggested that long-memory dynamics may prove to be an important element of those characterizations.

Ref.[17] in an article entitled "Long memory in stock returns" investigated a set of monthly stock index returns for long memory and applied a wide range of parametric and semi parametric estimators in an effort to obtain inference that are robust to the non-normality in the returns data. The study considered markets which differ widely in terms of capitalization, sophistication and microstructure to ensure robustness. The results showed that semi-parametric methods provide strong evidence of long memory in South Korean returns and some evidence of long-range dependence in the German, Japanese and Taiwanese returns series. The other returns series were consistent with short memory. The results also suggested that long horizon predictability of stock returns for UK, US, Hong Kong, Singapore and Australia is more likely to arise from time variation in expected returns or speculative bubbles than long memory.

Ref.[18] in an article entitled "Long memory property of stock returns; evidence from India" examined the presence of long memory in asset returns in the Indian stock market. They found that although daily returns are largely uncorrelated, there is strong evidence of long memory in its conditional variance. They concluded that FIGARCH is the best-fit volatility model and it outperforms other GARCH type models. They also observed that the leverage effect is insignificant in SenSex returns and hence symmetric volatility models turn out to be superior as they expected.

\section{LONG MEMORY THORETICAL ISSUES}

Traditional stationary ARMA processes have short memory in the sense that the autocorrelation function decays exponentially. When the sample autocorrelation decays very slowly, traditional stationary ARMA processes usually result in an excessive number of parameters.

A stationary process has long memory, or long range dependence, if its autocorrelation function behaves like.

$$
\rho(k) \rightarrow C_{p}^{k^{-\alpha}} \text { as } k \rightarrow \infty
$$

where $C_{P}$ is a positive constant, and $\alpha$ is a real number between 0 and 1.Thus the autocorrelation function of a long memory process decays slowly at a hyperbolic rate. In fact, it decays so slowly that the autocorrelations are not summable [19]:

$$
\sum_{k=-\infty}^{\infty} \rho^{(k)}=\infty
$$

\section{A. Long Memory GARCH Models}

Following [1], the process $\{\mathcal{E}\}$ is said to follow an ARCH model if

$$
\varepsilon_{t}=\sigma_{t} z_{t}
$$

where $E_{t-1}\left(z_{t}\right)=0$ and $\operatorname{Var}_{t-1}\left(z_{t}\right)=1$, and $\sigma_{t}$ is measurable with respect to the time t-1 information set. Conditional variance of the $\operatorname{ARCH}(q)$ model can be written as a linear function of past squared values of the process,

$$
\sigma_{t}^{2}=\alpha_{0}+\alpha_{1} \varepsilon_{t-1}^{2}+\Lambda+\alpha_{q} \varepsilon_{t-q}^{2}
$$

where $\alpha_{0}>0$ and $\alpha_{1}, \Lambda, \alpha_{q} \geq 0$. This model captures the tendency for volatility clustering, that is, for large (small) price changes to be followed by other large (small) price changes. [20], extended the ARCH class of models to the generalized $\mathrm{ARCH}$, or GARCH which has an autoregressive moving average form for the conditional variance $\sigma_{t}^{2}$. Conditional variance of the $\operatorname{GARCH}(p, q)$ model is expressed as

$$
\begin{aligned}
\sigma_{t}^{2} & =\alpha_{0}+\alpha_{1} \varepsilon_{t-1}^{2}+\Lambda+\alpha_{q} \varepsilon_{t-q}^{2}+\beta_{1} \sigma_{t-1}^{2}+\Lambda+\beta_{p} \sigma_{t-p}^{2} \\
& =\omega+\alpha(L) \varepsilon_{t}^{2}+\beta(L) \sigma_{t}^{2}
\end{aligned}
$$


where $\omega>0$. and $\alpha_{1}, \Lambda, \alpha_{q}, \beta_{1}, \Lambda, \beta_{q} \geq 0 . \alpha(L)$ and $\beta(L)$ are the lag polynomials with orders of $q$ and $p$ respectively. That is, by adding a parameter $p$ to the ARCH model, longer lags can be considered in the GARCH model with low orders. The GARCH $(p, q)$ process in Eq.(4.38) can be rewritten as an ARMA process in $\varepsilon_{t}^{2}$.

$$
\left[1-\alpha(L)-\beta(L) \varepsilon_{t}^{2}=\omega+[1-\beta(L)] v_{t}\right.
$$

where $v_{t} \equiv \varepsilon_{t}^{2}-\sigma_{t}^{2}$.The $\left\{v_{t}\right\}$ process is interpreted as the innovations for the conditional variance. To ensure conditional variance to be nonnegative, it is assumed that all the roots of the polynomial $[1-\beta(L)]$ lie outside the unit circle.

To take account of a unit root in the autoregressive polynomial $[1-\alpha(L)-\beta(L)],[21]$, introduced the IGARCH model. The IGARCH $(p, q)$ process is given by

$$
\phi(L)[1-L] \varepsilon_{t}^{2}=\omega+[1-\beta(L)] v_{t}
$$

where $\phi(L)=[1-\alpha(L)-\beta(L)][1-L)^{-1}$. In the IGARCH process, current information remains important for the forecast of the conditional variance for all horizons.

To capture long-range dependence in volatility, [7] extended the IGARCH mode in the Eq 6 to the FIGARCH model. A FIGARCH process of order $(p, d, q)$ is defined by

$$
\phi(L)(1-L)^{d} \varepsilon_{t}^{2}=\omega+[1-\beta(L)] v_{t}
$$

where the parameter $d$ is allowed to be any real number between 0 and 1 and $\phi(L)=1-\phi L-\Lambda-\phi_{q} L^{q}$, and $\beta(L)=\beta_{1} L+\Lambda+\beta_{P} L^{P}$. All the roots of $\phi(L)$. and $[1-\beta(L)]$ lie outside the unit circle. In Eq.(7), persistence of shocks to the conditional variance, or the degree of long-term dependencies is measured by the fractional differencing parameter $d$. From the fact that Eq.(7) is identical to the $\operatorname{GARCH}(p, q)$ model for $d=0$ and to the $\operatorname{IGARCH}(p, q)$ model for $d=1$, we can see that the FIGARCH process includes the GARCH and IGARCH processes as special cases [22].

The FIGARCH model directly extends the ARMA representation of squared residuals, which results from the GARCH model, to a fractionally integrated model. However, to guarantee that a general FIGARCH model is stationary and the conditional variance $\sigma_{t}^{2}$ is always positive, usually complicated and intractable restrictions have to be imposed on the model coefficients.

Noting that, an EGARCH model can be represented as an ARMA process in terms of the logarithm of conditional variance and thus always guarantees that the conditional variance is positive.

[12] proposed the following fractionally integrated EGARCH (FIEGARCH) model:

$$
\ln \left(\sigma_{t}^{2}\right)=\omega_{t}+(1+\psi L)(1-\phi L)^{-1}(1-L)^{-d} g\left(\varepsilon_{t}\right)
$$

$$
\phi(L)(1-L)^{d} \ln \sigma_{t}^{2}=\alpha+\sum_{j=1}^{q}\left(b_{j}\left|x_{t-j}\right|+\gamma_{j} x_{t-j}\right)
$$

where $\phi(L)$ is defined as earlier for the FIGARCH model, $\gamma_{j} \neq 0$ allows the existence of leverage effects, and $x_{t}$ is the standardized residual:

$$
x_{t}=\frac{\varepsilon_{t}}{\sigma_{t}}
$$

[12] showed that the FIEGARCH model is stationary If 0 $<\mathrm{d}<1[19]$.

\section{MODEL SPECIFICATION AND HYPOTHESIS TESTING}

To test the long memory properties of the Indian stock markets we set the following hypotheses:

$$
\mid \begin{aligned}
& H_{0}: \mathrm{d}=0 \text { or } \mathrm{d}=1 \\
& H_{1}: 0<d<1
\end{aligned}
$$

Following [13] we choose the $\operatorname{FIEGARCH}(1, d, 1)$ model to study the long memory property of volatility of the Indian stock returns.Also we selected the AR(1) process for mean equation of the series.

$$
\begin{gathered}
r_{t}=\omega+\alpha_{1} r_{t-1}+\varepsilon_{t} \\
g\left(\varepsilon_{t}\right)=\theta \varepsilon_{t-1}+\gamma\left[\left|\varepsilon_{t-1}\right|-E\left|\varepsilon_{t-1}\right|\right] \\
\omega_{t}=\omega+\ln \left(1+\delta N_{t}\right)
\end{gathered}
$$

Parameters of the above model are estimated by the maximum likelihood estimation.

\section{DATA AND EMPIRICAL RESULTS}

\section{A. Data}

The required data including 2108 daily closing observation for BSE500 price index covering the period $26 / 7 / 2000$ through 20/01/2009 were obtained from the Bangalore Stock Exchange, and were based on daily closing prices. The BSE500 returns $\left(r_{t}\right)$ at time $\mathrm{t}$ are defined in the logarithm of BSE500 indices (p), that is,

$$
r_{t}=\log \left(p_{t} / p_{(t-1)}\right)
$$

\section{B. Empirical Analysis}

Visual inspection of the plots of residuals of daily returns series of BSE500, shown below, proved very useful. It can be seen that from Figs 1 and 2 that return fluctuates around mean value that is close to zero. Volatility is high for certain time periods and low for other periods. The movements are in the positive and negative territory and larger fluctuations tend to cluster together separated by periods of relative calm. 
The volatility was highest in 2004 and 2008 .Thus Figs show volatility clustering, where large returns tend to be followed by small returns leading to continuous periods of volatility and stability. Volatility clustering implies a strong autocorrelation in squared return. Although there is little serial correlation in the time series BSE itself, it seems that both large changes and small changes are clustered together, which is typical of many high frequency macroeconomic and financial time series To confirm this conjecture, we use the ACF to look at the autocorrelation plots of BSE500 returns and its squared returns (Fig 3). Obviously, there is no autocorrelation in the return series itself, while the squared returns exhibit significant autocorrelation at least up to lag 6 . Since the squared returns measure the second order moment of the original time series, this result indicates that the variance of BSE500 conditional on its past history may change over time, or equivalently, the time series BSE500 may exhibit time varying conditional heteroskedasticity or volatility clustering.

Descriptive statistics are reported in table1. Generally the index has a large difference between its maximum and minimum returns. .The mean daily return is 0.000185 . The volatility (measured as a standard deviation) which is 0.007445 indicating a high level of fluctuations of the BSE500 returns. There is indication of negative skewness $(\mathrm{Skw}=-0.90673)$ which indicates that the lower tail of the distribution is ticker than the upper tail, that is ,the index declines occur more often than its increases. It means left tail is particularly extreme, an indication that the BSE500 has non-symmetric returns (see Fig 4). The kurtosis coefficient is positive, having high value for the return series (Kurt $=8.294)$ which is the pointer of leptokurtosis or fat taildness in the underlying distribution. In fact, under the null hypothesis of normality the Jarque-Bera statistic asymptotically follows a Qi-square distribution with 2 degree of freedom. The computed value of 2750 with Pvalue of zero, rejects the normality assumption due to the high kurtosis. Figure 1,2,3 presents the pattern of the returns series of BSE500 index series for the period under review. The index looks like a random walk. The Q-Q plot that presented in Fig 5 also shows that the return distribution also exhibits fat tails confirming the results in table1.

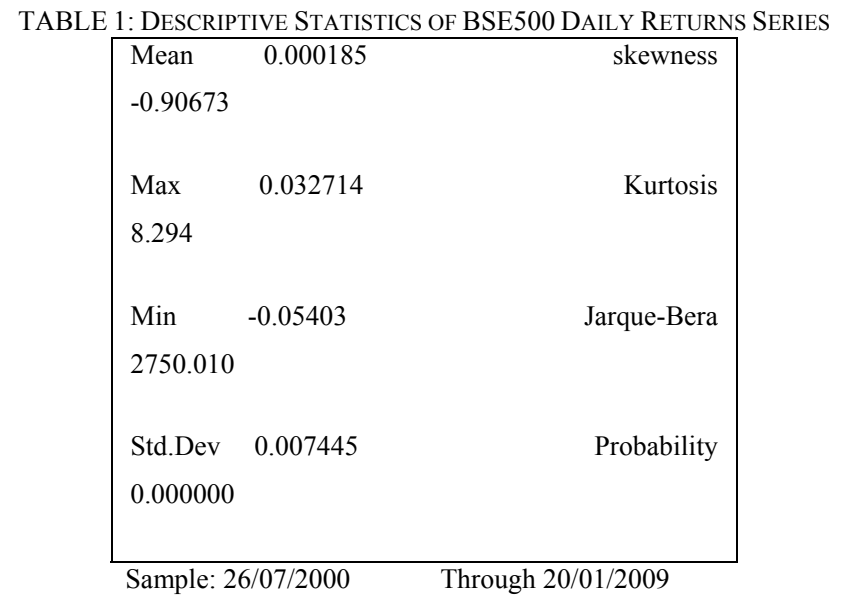

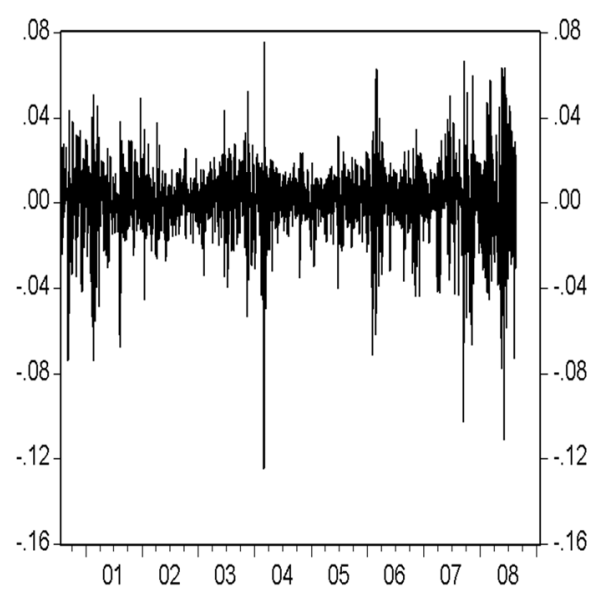

Figure 1: The Residuals of BSE500 Returns Series

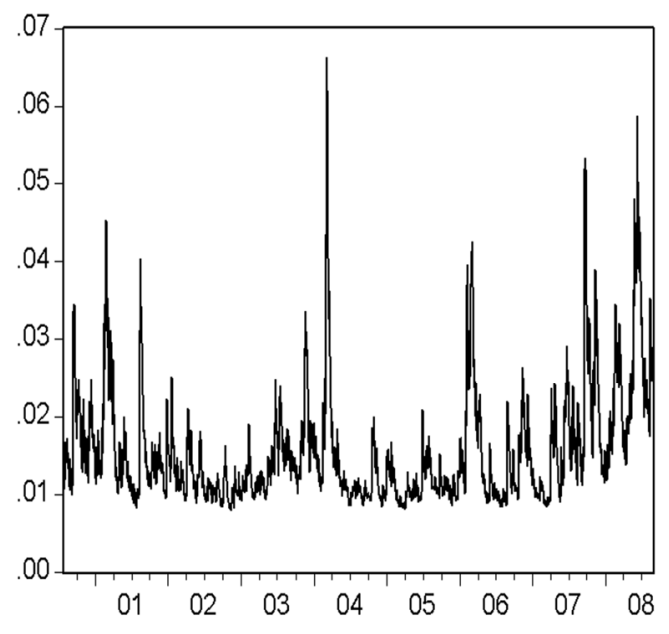

Figure 2 :GARCH Series of BSE500
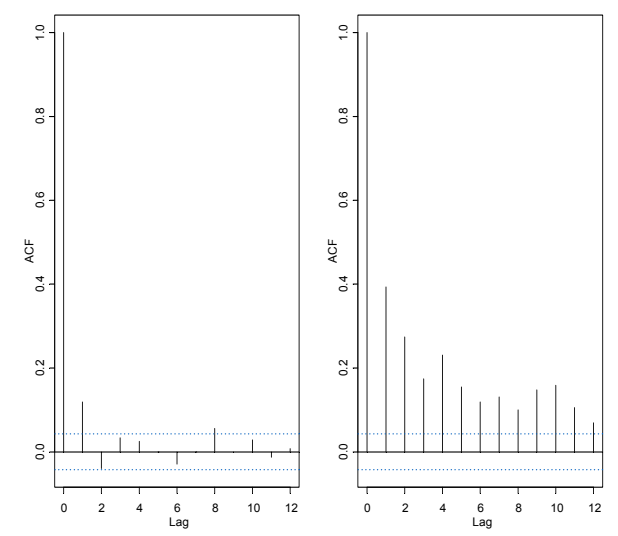

Figure 3 : ACF of BSE500 returns series for standard and squared residuals 


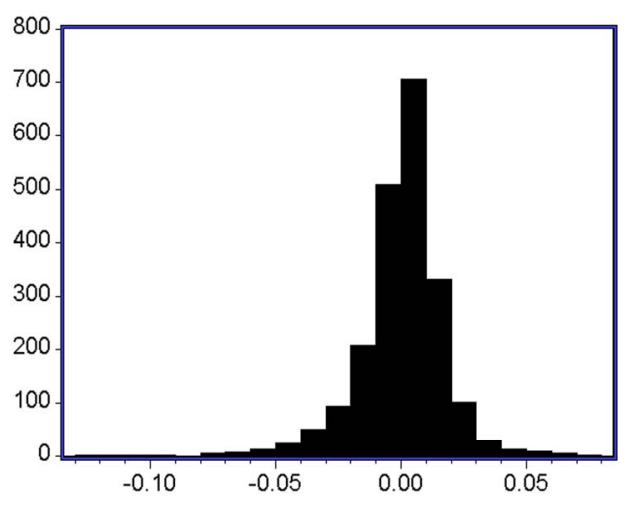

Figure 4 : Distribution of BSE500 Daily Returns Series

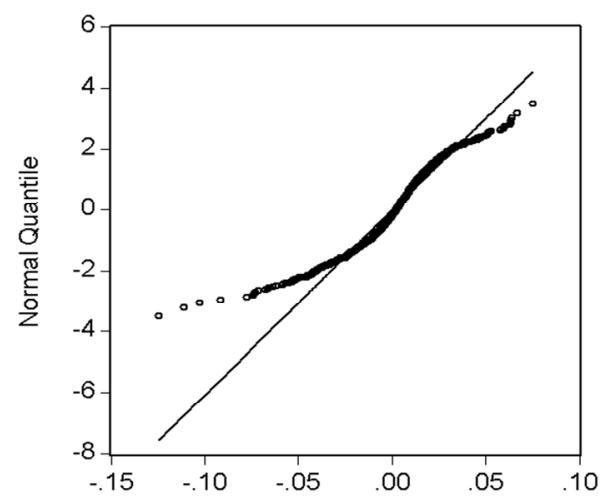

Before modelling long memory, we make sure of ARCH effect in the underlying series. As table 2 shows ARCH-LM test is statistically significant which indicates the presence of ARCH effect in the residuals of mean equation of BSE500.Therefore applying ARCH-type models are appropriate.

\begin{tabular}{|c|c|c|}
\hline \multicolumn{3}{|c|}{ TABLE 2: ARCH-LM TEST } \\
\hline \multicolumn{3}{|c|}{ ARCst } \\
\hline Statistics & Value & P-Value \\
\hline LM-Test & 431.5757 & 0.0000 \\
& & \\
\hline
\end{tabular}

The ADF test statistics rejects the hypothesis of unit root in the returns series at $1 \%$ level of significance. A formal application of ADF test on log returns, as shown in table 3 rejects the null hypothesis of a unit root in the return series. These properties of the BSE500 returns series are consistent with other financial times series.

Figure 5: Q-Q Plot of BSE500 Daily Returns Series

\begin{tabular}{|c|c|c|c|c|}
\hline \multirow[t]{3}{*}{ Variables } & \multicolumn{4}{|c|}{ Period 2000-2009 } \\
\hline & \multirow[t]{2}{*}{ Augmented Dickey-Fuller test statistic } & \multicolumn{3}{|c|}{ Test critical values } \\
\hline & & $1 \%$ & $5 \%$ & $10 \%$ \\
\hline PT & -1.107632 & -3.433256 & -2.862710 & -2.567439 \\
\hline LOGRT & -40.68433 & -3.433256 & -2.862710 & -2.567439 \\
\hline
\end{tabular}

In this case, the P-value is essentially zero, which is smaller than the conventional 5\% level, so we reject the null hypothesis that there are no $\mathrm{ARCH}$ effects.

Long memory

Since daily returns usually have a mean very close to zero, the absolute return is sometimes used as a measure of volatility. The plotted sample autocorrelation function of the daily absolute returns are as Fig 6.

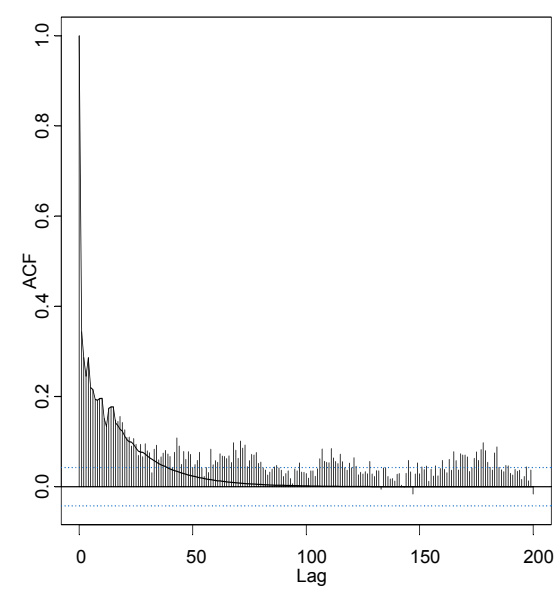

Figure 6: Sample Autocorrelation Function of the Daily Absolute Returns 
As Fig 6 shows the autocorrelation of absolute returns is highly persistent and remains very significant at lag 100 .

Before testing for long memory, we modelled volatility using symmetric and asymmetric ARCH-type models. Using AIC, BIC and log likelihood information criterion and after all post hoc analysis we choose the GARCH $(1,1)$, TGARCH $(1,1)$ and EGARCH $(1,1)$. Since the results of estimated asymmetric models confirmed the existence of leverage effects in the underlying series and FIEGARCH model simultaneously can captures long memory and leverage effects, the study applies FIEGARCH model. To test the null hypothesis of no long memory we specified FIEGARCH $(1, \mathrm{~d}, 1)$ model. The estimated coefficients of models are reported in the table 4. As it is shown all estimated coefficients are significant and we can concluded that the estimated models are correctly specified. In the FIEGARCH $(1, \mathrm{~d}, 1)$ model when fraction term is $0<\mathrm{d}<0.5$ the underlying series is stationary and has long memory; and when $-1 / 2<\mathrm{d}<0$, the underlying series is stationary but has short memory.

The summary of the information related to coefficients of all models are reported in the Table 4.

TABLE 4: COEFFICIENTS OF ESTIMATED MODELS

\begin{tabular}{|c|c|c|c|c|}
\hline Model & 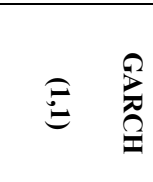 & 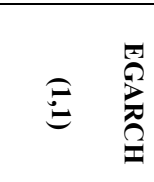 & $\stackrel{\vec{\Omega}}{\stackrel{\theta}{*}}$ & $\stackrel{2}{2}$ \\
\hline $\begin{array}{l}\text { Intercept- } \\
\text { Mean. }\end{array}$ & $5.769 \mathrm{e}-004$ & 0.000274 & $3.379 \mathrm{e}-004$ & 0.0002941 \\
\hline AR (1) & $1.331 \mathrm{e}-001$ & 0.160105 & $1.512 \mathrm{e}-001$ & 0.1651584 \\
\hline $\begin{array}{l}\text { Intercept- } \\
\text { Variance }\end{array}$ & $2.061 \mathrm{e}-006$ & -1.105315 & $3.125 \mathrm{e}-006$ & -0.3930549 \\
\hline $\begin{array}{l}\text { ARCH } \\
\text { Term }\end{array}$ & $1.726 \mathrm{e}-001$ & 0.293787 & $5.211 \mathrm{e}-002$ & 0.3108022 \\
\hline $\begin{array}{l}\text { GARCH } \\
\text { Term }\end{array}$ & $7.943 \mathrm{e}-001$ & 0.913590 & $7.634 \mathrm{e}-001$ & 0.5484113 \\
\hline Leverage & & -0.507723 & $2.321 \mathrm{e}-001$ & -0.1614701 \\
\hline Fraction & & & & 0.4254562 \\
\hline
\end{tabular}

In our estimated model, FIEGARCH $(1, \mathrm{~d}, 1)$, the fraction term is 0.43 which shows that the series shows long memory. Therefore, we conclude that the null hypothesis of no long memory cannot be accepted.

The estimated parameters for $\operatorname{FIEGARCH}(1, \mathrm{~d}, 1)$ are reported in the Table 5. As results show, all the estimated coefficients of the model are significant and we can conclude that the selected model is correct. The fraction term in the estimated model is 0.43 which indicate that the BSE500 returns series show long memory. The sum of $\mathrm{ARCH}$ and GARCH term also is less than 1 indicating that the series is stationary.
TABLE 5: ESTIMATED PARAMETERS OF FIEGARCH $(1, \mathrm{D}, 1)$

\begin{tabular}{|l|l|l|l|l|}
\hline & & & & \\
& & & & \\
\hline
\end{tabular}

Model Adequacy Test

After making sure of the accuracy of the estimated coefficient and selecting an appropriate order for selected models the next step is to check the adequacy of the selected models. To check the adequacy of the estimated model we applied to commonly used test i.e. Ljung-Box and ARCH LM tests.

If the value of the test statistic is greater than the critical value from the Q-statistics, then the null hypothesis can be rejected. Alternatively, if $p$-value is smaller than the conventional significance level, the null hypothesis that there are no autocorrelation will be rejected. In other words, the series under investigation shows volatility clustering or volatility persistence. The same is true for variance equation .The only difference is that in this case the test will be done on squared standardized residuals.

The results for Ljung-Box test are reported in the Table 6 . The test is for check the autocorrelation remain in the series. As results show the results for all model is insignificant and showing that there is no autocorrelation left in the models. It means the models adequately capture the autocorrelation in the underlying series. Therefore according to the results, the null hypothesis of no autocorrelation cannot be rejected.

TABLE 6: AUTOCORRELATION TEST

\begin{tabular}{|l|l|l|l|l|}
\hline Model & $\begin{array}{l}\text { LB* } \\
\text { Test } \\
\text { for } \\
\text { SR** }\end{array}$ & P-value & $\begin{array}{l}\text { LB test } \\
\text { for } \\
\text { SSR*** }\end{array}$ & P-value \\
\hline $\begin{array}{l}\text { GARCH } \\
(\mathbf{1 , 1})\end{array}$ & 18.93 & 0.09028 & 13.42 & 0.339 \\
\hline $\begin{array}{l}\text { EGARCH } \\
(\mathbf{1 , 1})\end{array}$ & 18.8 & 0.09351 & 9.729 & 0.6397 \\
\hline $\begin{array}{l}\text { TGARCH } \\
(\mathbf{1 , 1})\end{array}$ & 18.65 & 0.09743 & 9.492 & 0.6604 \\
\hline $\begin{array}{l}\text { FIEGARCH } \\
(\mathbf{1 , 1})\end{array}$ & 19.86 & 0.06975 & 11.4 & 0.4954 \\
\hline Ljung-Box & & & & \\
\hline
\end{tabular}


**Standardized Residuals

*** Squared Standardized Residuals

As another test for checking the adequacy of the model we applied ARCH-LM test. The results of the test for all models are reported in the Table 7.

\begin{tabular}{|l|l|l|l|l|}
\hline Model & LM & P-value & F-stat & P-value \\
\hline ARCH-4 & 10.36 & 0.5846 & 0.9463 & 0.6069 \\
& & & & \\
\hline GARCH(1,1) & 13.15 & 0.3582 & 1.203 & 0.3913 \\
\hline EGARCH(1,1) & 10.35 & 0.5854 & 0.9454 & 0.6077 \\
& & & & \\
\hline TGARCH(1,1) & 10.04 & 0.6122 & 0.9174 & 0.635 \\
& & & & \\
\hline FIEGARCH(1,d,1) & 11.45 & 0.4908 & 1.047 & 0.5145 \\
& & & & \\
\hline
\end{tabular}

The results show that the estimated models adequately capture the ARCH effects in the underlying series. Both LM and F-statistics are insignificant for all models indicating that there are no ARCH effects left in the model and the null hypothesis of no ARCH effects cannot be rejected. Therefore we concluded that all model are adequately capture the ARCH effect in the underlying series.

Finally we compared all estimated models based on AIC, BIC and Log likelihood information criterion. As results in the Table 8 shows, according to all criterion the FIEGARCH $(1, \mathrm{~d}, 1)$ model seems to provide a slightly better fit.

TABLE 8.COMPARISON OF ESTIMATED MODELS BASED ON INFORMATION

\begin{tabular}{|c|c|c|c|c|}
\hline \multicolumn{5}{|c|}{ CRITERION } \\
\hline Model & $\stackrel{\Omega}{\Xi}$ & 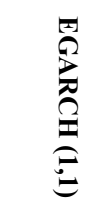 & 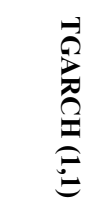 & 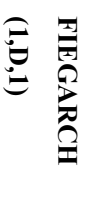 \\
\hline AIC & -15429 & -15466 & -15475 & -15494 \\
\hline BIC & -15400 & -15433 & -15441 & -15454 \\
\hline LOGLIK & 7719 & 7739 & 7744 & 7754 \\
\hline
\end{tabular}

\section{CONCLUSION}

This paper examined the presence of long memory in asset returns in the Indian stock market. Using BSE500 index in India, our study finds that there is strong evidence of long memory in its conditional variance. Various statistical tests are conducted to investigate the long memory property. It is observed that the FIEGARCH $(1, d$, 1) is the best-fit volatility model and it outperforms other GARCH-type models. Dislike the previous study (Banerjee and Sarkar, 2006), it is also observed that the leverage effect is significant in BSE500 returns and hence asymmetric volatility models turn out to be superior, as expected. The presence of long memory in asset returns contradicts the weak form market efficiency hypothesis. These results have profound implications for the capital market regulator. First, asset prices are not random walk; second, volatility of asset returns can be modeled using returns from the recent as sell as remote past and hence derivative instruments can now be more efficiently priced; and third, a stock return generally follows a random walk with long memory in conditional volatility process [23].

\section{REFERENCES}

[1] F.R. Engle, (1982). Autoregressive conditional heteroskedasticity with estimates of the variance of United Kingdom inflation. Econometrica, 50 (4), 987-1007.

[2] M.J. Lombardi \& G.M. Gallo, (2002). Analytic hessian matrices and the computation of Figarch estimates [Online] Available: http://eprints.unifi.it/archive/00000111/00/wp2002_03.pdf

[3] C. W. J. Granger, (1980): "Long memory relationships and the aggregation of dynamic models," Journal of Econometrics, 14, 227238.

[4] C.W.J. Granger, and R. Joyeux, (1980). An introduction to longmemory time series models and fractional differencing, Journal of Time Series Analysis, 1,15- 29.

[5] J. R. M. Hosking, (1981): "Fractional differencing," Biometrika, 68, $165-176$.

[6] R. S. Deo, \& Hurvich, C.M.(2001).On the log periodogram regression estimator of the memory parameter in long memory stochastic volatility models, Econometric Theory, 17,686-710.

[7] R.T. Baillie, T. Bollerslev, and H.O. Mikkelsen, Fractionally integrated generalized autoregressive conditional heteroskedasticity, Journal of Econometrics, 1996. 74, 3-30.

[8] C.W.J. Granger, and Z. Ding, 1996, Modeling volatility persistence of speculative returns, Journal of Econometrics, 73, 185-215.

[9] J.M. Maheu (2002).Can GARCH models capture the long -range dependence in financial market volatility, studies in nonlinear dynamics and econometrics,9,(4),1-41.

[10] T. H.McCurdy, and P. K. Michaud (1997): "Capturing Long Memory in the Volatility of Equity Returns: a Fractionally Integrated Asymmetric Power ARCH Model," manuscript, Rotman School of Management, University of Toronto.

[11] Z. Ding, C.W.J. Granger, and R.F. Engle, (1993). A long memory property of stock returns and a new model, Journal of Empirical Finance, 1, 83-106.

[12] T. Bollerslev, and H.O. Mikkelsen, (1996). Modeling and pricing long memory in stock market volatility, Journal of Econometrics, 73, 151-84.

[13] C.Brunetti, and C. L. Gilbert (2000): "Bivariate FIGARCH and fractional cointegration," Journal of Empirical Finance, 7, 509-530.

[14] R. T.Baillie, Cecen A. A., and Y. Han (2000): "High frequency deutsche mark-us dollar returns: Figarch representations and non linearities," Multinational Finance Journal, 4(3-4), 247-67.

[15] A.Beltratti, and C. Morana, 2006, Breaks and persistency: macroeconomic causes of stock market volatility, Journal of Econometrics, 131, 151-71.

[16] J.T. Barkoulas, C.F. Baum, and N. Travlos, (2000). Long memory in the Greek stock market, Applied Financial Economics, 10, 177-84.

[17] O. T. Henry, (2002). Long memory in stock returns: some international evidence. Applied financial economics, 12,725-729.

[18] A. Banerjee, \& S. Sarkar, (2006). Long memory property of stock returns evidence from India, Working Paper No. 589 [Online] Available: http://www.iimcal.ac.in/res/upd\%5CWPS\%20589.pdf

[19] E. Zivot, and J. Wang, (2002). Modeling financial time series with splus, Springer.

[20] T. Bollerslev, (1986). Generalized autoregressive conditional heteroskedasticity, Journal of Econometrics 31, 307-327

[21] R. F. Engle, and T. Bollerslev (1986): "Modelling the persistence of conditional variances," Econometric Reviews, 5, 1-50.

[22] J. Lee, T.S. Kim,, \& H.K. Lee, (2000).Long memory in volatility of Korean stock market returns [Online] Available: http://koasas.kaist.ac.kr/bits tream/10203/4999/1/2000-178.pdf

[23] A. Banerjee, and S. Sarkar, (2006). Modeling daily volatility of the Indian stock market using intraday data, Working Paper No. 588 [Online].Available:

http://www.iimcal.ac.in/res/upd\%5CWPS\%20588.pdf 